\title{
Recommended minimal standards for describing new taxa of the family Halomonadaceae
}

D. R. Arahal, R. H. Vreeland, C. D. Litchfield, M. R. Mormile, B. J. Tindall, A. Oren, V. Bejar, E. Quesada and A. Ventosa

International Journal of Systematic and Evolutionary Microbiology (2007), 57, part 10, pp. 24362446

On page 2437, second paragraph, under the heading 'Salt/temperature/pH as preliminary tests', the name 'Zymomonas palmae' should read Zymobacter palmae. In addition, in Table 1 on page 2439, the last entry should be for the genus Zymobacter with the species Zymobacter palmae and not 'Zymomonas palmae'.

Sphingobium rhizovicinum sp. nov., isolated from rhizosphere soil of Fortunella hindsii (Champ. ex Benth.) Swingle

C. C. Young, A. B. Arun, P. Kämpfer, H.-J. Busse, W.-A. Lai, W.-M. Chen, F.-T. Shen and P. D. Rekha

International Journal of Systematic and Evolutionary Microbiology (2008), 58, part 8, pp. 1801-1806

The CCM accession number for the type strain of Sphingobium rhizovicinum sp. nov. should be CCM $7491^{\mathrm{T}}$ and not CCM $7941^{\mathrm{T}}$ as given in the abstract and species description.

Desulfovibrio marinisediminis sp. nov., a novel sulfate-reducing bacterium isolated from coastal marine sediment via enrichment with Casamino acids

S. Takii, S. Hanada, Y. Hase, H. Tamaki, Y. Uyeno, Y. Sekiguchi and K. Matsuura

International Journal of Systematic and Evolutionary Microbiology (2008), 58, part 10, pp. 24332438

NMRC $101113^{\mathrm{T}}$ given in the abstract and species description should be NBRC $101113^{\mathrm{T}}$. 